\title{
Photoelectrochemical characteristics of cells with dyed and undyed nanoporous p-type semiconductor $\mathrm{CuO}$ electrodes
}

Seiichi Sumikura, Shogo Mori, Sinya Shimizu, Hisanao Usami, and Eiji Suzuki*

Department of Fine Materials Engineering, Faculty of Textile Science and Technology, Shinshu

University, 3-15-1 Tokida, Ueda, Nagano 386-8567, Japan

* Eiji Suzuki, Ph.D.

Professor, Department of Fine Materials Engineering, Shinshu University,

3-15-1 Tokida Ueda 386-8567, Japan

E-mail:esuzuki@shinshu-u.ac.jp

Tel. +81-268-21-5456 Fax. +81-268-21-5456

\begin{abstract}
We prepared nanoporous p-type $\mathrm{CuO}$ semiconductor electrodes adsorbing various dyes with different HOMO levels and anchoring groups. Solar cells were fabricated by coupling each of the dyed electrodes with a platinum counter electrode and filled with electrolytes containing $\mathrm{I}^{-} / \mathrm{I}_{3}{ }^{-}$redox couple. Cathodic photocurrent due to hole injection from the adsorbed dye to the semiconductor was observed. Only the dyes with HOMO and LUMO potentials more positive than valence and conduction band edges, respectively, functioned as sensitizers for p-type dye-sensitized solar cells. Effects of annealing temperature and thickness of the $\mathrm{CuO}$ nanoporous membrane on cell performance were investigated as well.
\end{abstract}

Keyword:hole injection, potential difference, energy conversion efficiency, cathodic current

\section{Introduction}

Since a dye-sensitized solar cell (DSC) with 7\% solar to power conversion efficiency was reported by O'Regan and Grätzel in 1991 [1], DSCs have attracted attention due to their high efficiency and expected low production cost. To date, the highest reported efficiency, which is above $11 \%$, was achieved by a nanoporous $\mathrm{TiO}_{2}$ electrode sensitized with a $\mathrm{Ru}$ complex dye absorbing light between 400 and $800 \mathrm{~nm}$ of solar spectrum [2]. In order to increase the efficiency further, wider light spectrum should be harvested. However, it is not trivial to design single dye absorbing wide range of the spectrum. In addition, to exploit lower energy photons of near IR region, open circuit voltage $\left(V_{\mathrm{OC}}\right)$ of the solar cells must be decreased. A remedy of the issues is to introduce tandem structure to DSCs.

In 2000, He et al. reported a tandem solar cell using dye-sensitized $\mathrm{TiO}_{2}$ as a photo-anode and dye 
sensitized $\mathrm{NiO}$, a p-type semiconductor, as a photo-cathode for longer wavelength spectrum [3]. Dye sensitization of the photo-cathode occurs due to hole injection from the adsorbed dye to the NiO. The photo-anode and -cathode were connected in series through an electrolyte containing $\mathrm{I}^{-} / \mathrm{I}_{3}{ }^{-}$redox couple. For the case, $V_{\mathrm{OC}}$ becomes the potential difference between the Fermi levels of the $\mathrm{TiO}_{2}$ and $\mathrm{NiO}$. In principle, the same values of $J_{\mathrm{SC}}$ can be obtained from the anode and cathode by using dyes absorbing equal number of photons, and thus, a higher efficiency can be expected for the tandem DSCs than conventional one.

At the moment, efficiency of dye-sensitized p-type metal oxide semiconductor is very low, which limits the efficiency of the tandem cell using dye-sensitized n- and p-type metal oxide electrodes ( $\mathrm{n} / \mathrm{p}$ DSCs). The highest reported values for dye-sensitized $\mathrm{p}$-type metal oxide solar cells ( $\mathrm{p}$-DSC) using $\mathrm{NiO}$ were $1 \mathrm{mAcm}^{-2}$ of $J_{\mathrm{SC}}$ and $80 \mathrm{mV}$ of $V_{\mathrm{OC}}[4,5]$. The reasons of low efficiency have not been understood yet, and knowledge of p-type semiconductors as hosts of dye-sensitization is limited. In order to expand knowledge and understanding of p-type dye-sensitization for solar cells, we studied photocurrent characteristics of $\mathrm{CuO}$ nanoporous electrodes instead of $\mathrm{NiO}$ electrodes used by $\mathrm{He}$ et al. as photo-cathodes adsorbing various dyes with the different highest occupied molecular orbital (HOMO) and lowest unoccupied molecular orbital (LUMO) levels, comparing with that of undyed $\mathrm{CuO}$ nanoporous electrodes.

A widely recognized concept how p-type dye-sensitized cells function is the following: the hole injection is electron transfer from the valence band of the semiconductor to the vacant HOMO of the photoexcited dye [6]. The injected holes diffuse to the back contact, and electrons photoexcited from the HOMO to the LUMO transfers to $\mathrm{I}_{3}{ }^{-}$in the electrolyte, yielding cathodic photocurrent [4]. Discussion in this study is mainly based on this concept ${ }^{1}$.

$\mathrm{CuO}$ is a p-type semiconductor whose bandgap is $1.4 \mathrm{eV}$ [7]. The dyes examined here have the potential difference between the HOMO and LUMO larger than $1.4 \mathrm{eV}$. Therefore, they are not suitable for expanding photoactive spectrum of $\mathrm{CuO}$ electrode to a longer wavelength range. The dyes, however, are expected to enhance photocurrent in the range of $\mathrm{CuO}$ absorbing spectrum, and the primary aim of the study here is to investigate conditions giving the hole injection at electrolyte/dye/CuO interfaces. Along the purpose, we selected dyes having various HOMO levels relative to the valence band edge potential of $\mathrm{CuO}$ and different anchoring groups.

\section{Experimental}

Porous $\mathrm{CuO}$ film was prepared by applying $\mathrm{CuO}$ slurry (C.I. KASEI. Co., Ltd.) on FTO (9.5 $\Omega$ / square; Nippon Sheet Glass Co., Ltd) by doctor blade method using mending tape (Scotch ${ }^{\circledR}$ ) as a spacer. The film was annealed at $300^{\circ} \mathrm{C}, 400^{\circ} \mathrm{C}$ or $500^{\circ} \mathrm{C}$ for $30 \mathrm{~min}$. The film was characterized by XRD measurements (Rigaku RINT system, $\mathrm{CuK} \alpha$ ) and field emission-scanning electron microscopy (FE-SEM; HITACHI S-5000). Thickness of the films was measured with a surface profiler 
(KLA-Tencor Co. Ltd., Alpha-step 500).

For sensitization, we examined four dyes; NK-2612, NK-3628 (Hayashibara Biochemicals Laboratories., Inc.), Fast Green FCF (Wako Pure Chemical Industries, Ltd.), and N3 (Peccell Technologies, Inc.). Figure 1 shows structure of these dyes. Absorption peak $\left(\lambda_{\max }\right)$, the Highest Occupied Molecular Orbital (HOMO) and the Lowest Unoccupied Molecular Orbital (LUMO) potentials of the dyes were determined as follows. Oxidation potentials of ground state dyes were measured by cyclic voltammetry (CV) or differential pulse voltammetry (DPV) using an electrochemical analyzer (model 650A, ALS instruments), and used as the HOMO potentials in our study. Reference electrode was $\mathrm{Ag} / \mathrm{AgCl}$, and working and counter electrodes were Pt wires. The optical absorption spectra in the range 400-900 $\mathrm{nm}$ were recorded with spectrophotometer (U-4100; HITACHI., Ltd.). Fluorescence spectrum measurement (F-4500; HITACHII., Ltd.) was carried out for the solutions containing 0.1-0.01 $\mathrm{mM}$ of the dyes in a quartz cell. They were bubbled with argon or nitrogen gas for 5 minutes before measurements. Stray light was cut with a bandpass filter. The energy gap of dyes $\left(\mathrm{E}_{\mathrm{g}}\right)$ was calculated from equation 1 with long wavelength of absorption edge $\left(\lambda_{1}\right)$ or short wavelength of fluorescence edge $\left(\lambda_{2}\right)$. $\lambda_{1}$ was used when fluorescence was not observed. $\mathrm{E}_{\mathrm{g}}=\mathrm{h} v_{1 \text { or } 2}(\mathrm{~J})=1240 / \lambda_{1 \text { or } 2}(\mathrm{eV})$,

where $\mathrm{h}$ is Planck constant, $v$ frequency, and $\lambda$ the wavelength of the absorption or fluorescence edge.

LUMO potential was calculated by using Eq. (2) ${ }^{2}$.

$\mathrm{LUMO}=\mathrm{HOMO}-\mathrm{E}_{\mathrm{g}}$

DSCs were fabricated by coupling the dye-adsorbed films with Pt/Pd sputtered FTO as a counter electrode, and by filling between the two electrodes an electrolyte containing $0.05 \mathrm{M} \mathrm{I}_{2}, 0.1 \mathrm{M} \mathrm{LiI}$, 0.6 M 1,2-Dimethyl-3-propylimidazolium iodide (DMPII), and $0.5 \mathrm{M}$ 4-tert-butylpyridine in acetonitrile. I-V characteristics were measured using solar simulator (AM1.5 $100 \mathrm{mWcm}^{-2}$, YSS-100, Yamashita Denso Co. Ltd.) and a cyclic voltammetry tool (HSV-100; Hokuto Denko Co., Ltd.). For incident photon to current conversion efficiency (IPCE) measurement, DSCs were irradiated with monochromatic light and short circuit current was measured with a digital multimeter. IPCE was obtained by Eq. (3).

$\operatorname{IPCE}(\%)=1240\left(J_{\mathrm{SC}} / \lambda \phi\right) \times 100$,

where $J_{\mathrm{SC}}$ is short circuit current density $\left(\mathrm{mAcm}^{-2}\right), \lambda$ wavelength of monochromatic light (nm), and $\phi$ intensity of monochromatic light $\left(\mathrm{mWcm}^{-2}\right)$.

\section{Result and Discussion}

\subsection{XRD measurements}

Figure 2 shows $\mathrm{XRD}$ pattern of $\mathrm{CuO}$ film annealed at $300^{\circ} \mathrm{C}$. All peaks were assigned to those of $\mathrm{CuO}$ but not of $\mathrm{Cu}_{2} \mathrm{O}$ by comparing the peak position with JCPDS card No.50611, 50667. Crystal 
size was estimated by using Scherrer equation:

$\mathrm{D}=\mathrm{K} \times \lambda /(\mathrm{b} \times \cos \theta)$,

where $\mathrm{D}$ is primary particle size, $\mathrm{K}$ constant, 0.9 in this case, $\lambda$ X-ray wavelength $(0.15421 \mathrm{~nm}$; $\mathrm{CuK \alpha}$ ), b half width (rad), and $\theta$ reflection angle. The estimated particle size was $16 \mathrm{~nm}$.

\subsection{Dye-sensitization}

Eelectrochemical and light-absorbing characteristics of the dyes determined in this study were summarized in Table1.

Photo-electrochemical characteristics of the cells fabricated using the dye-adsorbed and non-adsorbed $\mathrm{CuO}$ electrodes are measured using the solar simulator. Figure 3 shows I-V characteristics of the cells. The cells exhibited the highest $J_{\mathrm{SC}}$ with Fast Green FCF and the highest $V_{\mathrm{OC}}$ with NK-3628 when irradiated. The photon-to-current conversion efficiency of the cells was enhanced 5.3 and 3.6 fold by dying with Fast Green FCF and with NK-3628 dyes, respectively, in comparison with the undyed $\mathrm{CuO}$ cell. On the other hand, $\mathrm{N} 3$ dye reduced the cell efficiency to $1 / 20$ of the undyed $\mathrm{CuO}$ cell. To further examine characteristics of the increase or decrease in the efficiency with dyeing, incident photon to current efficiency (IPCE) at each wave length was measured (Fig.4). IPCE peaked at around 620 and $790 \mathrm{~nm}$ for Fast Green FCF and NK-3628, respectively. The peak wavelength is close to the absorption maximum wavelength $\left(\lambda_{\max }\right)$ of Fast Green FCF, $615 \mathrm{~nm}$ and of NK-3628, $752 \mathrm{~nm}$, respectively. These results indicated the CuO electrodes were dye-sensitized by Fast Green FCF and NK-3628. Since the current was enhanced to cathodic direction, the authors concluded that hole injection caused the dye-sensitization. NK-2612 dye did not show any IPCE peak in the wavelength range corresponding to the dye absorption. N3 dye showed IPCE valley instead of peak in the wavelength range corresponding to the dye absorption, indicating that dying with $\mathrm{N} 3$ depressed photocurrent generated by direct excitation of $\mathrm{CuO}$, in other words, $\mathrm{N} 3$ dye exhibited negative dye-sensitization for p-type $\mathrm{CuO}$ electrode. In some cases, $\mathrm{CuO}$ electrode dyed with $\mathrm{N} 3$ generated anodic current (data not shown) instead of cathodic one.

The inset of Figure 4 shows absorption spectra of the dyed and undyed $\mathrm{CuO}$ electrodes. Although the $\mathrm{CuO}$ electrodes were thin, $\mathrm{CuO}$ itself absorbed most of visible light. Absorption due to the adsorbed dye was seen only for NK-3628. However the cell with undyed $\mathrm{CuO}$ did show much lower performance than the cells dyed with Fast Green FCF and NK-3628 as shown in Figure 3. The fact suggested that electrons and holes generated by direct excitation of semiconductor $\mathrm{CuO}$ tend to quickly recombine, resulting in the low cell efficiency, while with dye-sensitization only the holes are injected to $\mathrm{CuO}$ and the excited electrons in the dye molecules are transferred to $\mathrm{I}_{3}{ }^{-}$in redox solution, resulting in better charge separation and consequently the higher cell efficiency. Defect sites in nanoporous $\mathrm{CuO}$ film can be recombination sites; $\mathrm{CuO}$ used in this study are far from 
defectless crystals and expected to have many defect sites.

\section{3 $\mathrm{CuO}$ band edge potentials relative to HOMO and LUMO}

The valence band edge was estimated as sum of the open circuit voltage $\left(V_{\mathrm{OC}}\right)$ and $\mathrm{I}^{-} / \mathrm{I}_{3}{ }^{-}$redox potential. The value of Voc is the difference between the redox potential of the electrolyte and the Fermi level of p-type semiconductor. Here, we assume the Fermi level is located close to the valence band edge. Observed Voc of $0.08 \mathrm{~V}$, and the $\mathrm{I}^{-} / \mathrm{I}_{3}{ }^{-}$redox potential of $0.44 \mathrm{~V}$ vs. NHE [8] yielded the valence band edge potential $\mathrm{E}_{\mathrm{VB}}$ of $0.52 \mathrm{~V}$ vs. NHE. The conduction band edge potential $\mathrm{E}_{\mathrm{CB}}$ of $\mathrm{CuO}$ was estimated as $-0.8 \mathrm{~V}$ vs. NHE by subtracting the band gap energy from the valence band edge potential.

Potentials of the valence and conduction band edges of $\mathrm{CuO}$ and the HOMO and LUMO of the dyes are shown in Figure 5. HOMO levels of Fast Green FCF, N3 and NK-3628 seem to be deep enough to inject holes into the valence band. Among them, the potential difference between the Fast Green FCF HOMO and $\mathrm{E}_{\mathrm{VB}}$ is largest, seeming to give the fastest hole injection rate and resulting in the highest cell performance.

The HOMO level of NK-2612 does not seem to be sufficiently deeper than $E_{V B}$ to inject holes to the valence band, which is consistent with no dye-sensitization observed for this dye.

The LUMO level of $\mathrm{N} 3$ is sufficiently above $\mathrm{E}_{\mathrm{CB}}$ to inject the photoexcited electrons from the dye to the conduction band; the injected electrons would recombine in $\mathrm{CuO}$ with the holes generated by direct excitation of $\mathrm{CuO}$ or injected from $\mathrm{N} 3$ dye, which explains the observed negative dye-sensitization and anodic current exhibited in some cases by N3 dye. Since the HOMO level of $\mathrm{N} 3$ is sufficiently deeper than $\mathrm{E}_{\mathrm{VB}}$, there may be considerable hole injection. However since the LUMO is distributed closer to the semiconductor than the HOMO in adsorbed N3 [9], the electron injection from the dye to $\mathrm{CuO}$ possibly overwhelms the hole injection.

The LUMO levels of Fast Green FCF and NK-3628 are below $\mathrm{E}_{\mathrm{CB}}$ and consequently no electron injection seems to occur, resulting in less recombination of the electrons and holes in $\mathrm{CuO}$.

\subsection{Calcination temperature of $\mathrm{CuO}$ electrode}

Figure 6 shows FE-SEM images of $\mathrm{CuO}$ electrodes annealed at $300^{\circ} \mathrm{C}, 400^{\circ} \mathrm{C}$ or $500^{\circ} \mathrm{C}$. As the temperature increased, larger particles were formed, probably due to melting of boundaries between particles. Table 2 shows I-V characteristic of the cells dyed with Fast Green FCF. The cells showed lower $J_{\mathrm{SC}}$ with $\mathrm{CuO}$ electrode annealed at $500^{\circ} \mathrm{C}$ than at 300 and $400^{\circ} \mathrm{C}$, which could be due to the smaller dye adsorbing surface area of the larger particles formed at $500^{\circ} \mathrm{C}$.

\subsection{Film thickness}

Figure 7 shows $J_{\mathrm{SC}}, V_{\mathrm{OC}}$, and the efficiency of p-DSCs of different $\mathrm{CuO}$ thicknesses. Adsorbed dye 
was Fast Green FCF. The current density did not increase much with the thickness. This can be rationalized with the high absorption coefficient of $\mathrm{CuO}$.

\section{Conclusions}

DSCs constituted of nanoporous p-type semiconductor $\mathrm{CuO}$ film dyed with Fast Green FCF and NK-3628, respectively, functioned as p-type dye-sensitized solar cells. The HOMO and LUMO potentials of these dyes are more positive than the valence band and conduction band edges of the semiconductor, respectively, which is favorable for the hole injection to valence band and opposite to the electron injection to the conduction band. Contrarily, $\mathrm{CuO}$ electrode sensitized with $\mathrm{N} 3$ dye did not generate cathodic current. The LUMO level of N3 is more negative than the conduction band edge, probably resulting in electron injection from the dye to the conduction band and the concomitant recombination of the holes and electrons in the semiconductor. These facts indicated that the widely recognized working principle of n-type DSC is applicable to p-type DSC when inversely interpreted to fit to p-type behavior.

\section{Acknowledgements}

This work was supported by the Cooperative Link for Unique Science and Technology for Economy Revitalization (CLUSTER) of Ministry of Education, Culture, Sports, Science and Technology of Japan.

\section{Reference}

[1] B. O'Regan, M. Grätzel, Nature 353 (1991) 737-740.

[2] M. Grätzel, J. Photochem. Photobiol. A: Chem., 164 (2004) 3-14.

[3] J. He, H. Lindström, A. Hagfeldt and S.-E. Lindquist, Sol. Energy Mater. Sol. Cells 62 (2000) 265-273.

[4] J. He, H. Lindström, A. Hagfeldt, S.-E. Lindquist, J. Phys. Chem. B. 103 (1999) 8940-8943.

[5] A. Nakasa, H. Usami, S. Sumikura, S. Hasegawa, T. Koyama and E. Suzuki, Chem. Lett. 34 (2005) 500-501.

[6] T. Sakata, K. Hashimoto, and M. Hiramoto, J. Phys. Chem. 94 (1990), 3040-3045.

[7] J. Ghijsen, L. H. Tjeng, J. van Elp, H. Eskes, J. Westerink, G. A. Sawatzky and M. T. Czyzyk, Phys. Rev. B 38 (1988) 11322-11330.

[8] A. Hagfeldt and M. Grätzel, Chem. Rev. 95 (1995) 49-68.

[9] A. Hagfeldt and M. Grätzel, Acc.Chem. Res, 33 (2000), 269-277. 


\section{Footnote}

1. There may be surface states or other states in band gap into which the holes or electrons may be injected. Therefore comparing the HOMO and LUMO levels with the Fermi level may be more strict method. However, the authors follow for the time being the widely applied simplified model that the holes are injected from the HOMO to the valence band in p-type cells and the electrons are injected from the LUMO to the conduction band in n-type cells $[4,6]$. Therefore the authors compare the HOMO and LUMO levels with the valence and conduction band edges.

2. LUMO potential estimated by Eq.(2) is not based on one electron approximation, but includes the electron correlation. 


\section{Figure legends}

Figure 1. Structure of examined dyes

Figure 2. XRD pattern of $\mathrm{CuO}$ film annealed at $300^{\circ} \mathrm{C}$

Figure 3. I-V characteristics of p-DSCs using $\mathrm{CuO}$ electrodes dyed with four different dyes and an undyed $\mathrm{CuO}$ electrode. Irradiation intensity was $100 \mathrm{mWcm}^{-2}$.

Figure 4. IPCE of p-DSCs using $\mathrm{CuO}$ electrodes dyed with four different dyes and an undyed $\mathrm{CuO}$ electrode

Inset: Absorption spectra of each dyed and undyed nanoporous $\mathrm{CuO}$ electrode. $\mathrm{CuO}$ film thickness is $0.34,0.41,0.52,0.42$ and $0.36 \mu \mathrm{m}$ for Fast Green FCF dye, NK-3628, NK-2612, N3 and without dye

Figure 5. Energy diagram of the dyes and $\mathrm{CuO}$.

Figure 6. FE-SEM image of $\mathrm{CuO}$ film , annealed at a. $300^{\circ} \mathrm{C}$, b. $400^{\circ} \mathrm{C}$, c. $500^{\circ} \mathrm{C}$

Figure 7. $J_{\mathrm{SC}}, V_{\mathrm{OC}}$ and energy conversion efficiency of p-DSCs as a function of $\mathrm{CuO}$ electrode thickness. 


\section{Table 1}

HOMO and LUMO potential of dyes and peak wavelength of absorption.

\begin{tabular}{crrr} 
dye & $\lambda_{\max } /$ nm & $\begin{array}{c}\text { HOMO }^{a} \\
/ \mathrm{V}\end{array}$ & $\begin{array}{c}\text { LUMO }^{\mathrm{a}} \\
/ \mathrm{V}\end{array}$ \\
\hline Fast Green & 615 & 1.25 & -0.74 \\
NK-2612 & 786 & 0.60 & -0.88 \\
NK-3628 & 752 & 0.90 & -0.75 \\
N3 & 525 & 1.00 & -0.97 \\
\hline
\end{tabular}

a vs. NHE 
Table 2

$\mathrm{I}-\mathrm{V}$ characteristics of $\mathrm{p}$-DSCs prepared with different $\mathrm{CuO}$ annealing temperatures.

\begin{tabular}{rrrrr}
$\begin{array}{c}\text { Temperature } \\
/{ }^{\circ} \mathrm{C}\end{array}$ & $\begin{array}{c}J_{\mathrm{SC}} \\
/ \mathrm{mAcm}^{-2}\end{array}$ & \multicolumn{1}{l}{$\begin{array}{l}V_{\mathrm{OC}} \\
/ \mathrm{V}\end{array}$} & fill factor & $\eta / \%$ \\
\hline 300 & 0.30 & 0.115 & 0.31 & 0.011 \\
400 & 0.36 & 0.103 & 0.22 & 0.0083 \\
500 & 0.14 & 0.113 & 0.17 & 0.0028 \\
\hline
\end{tabular}




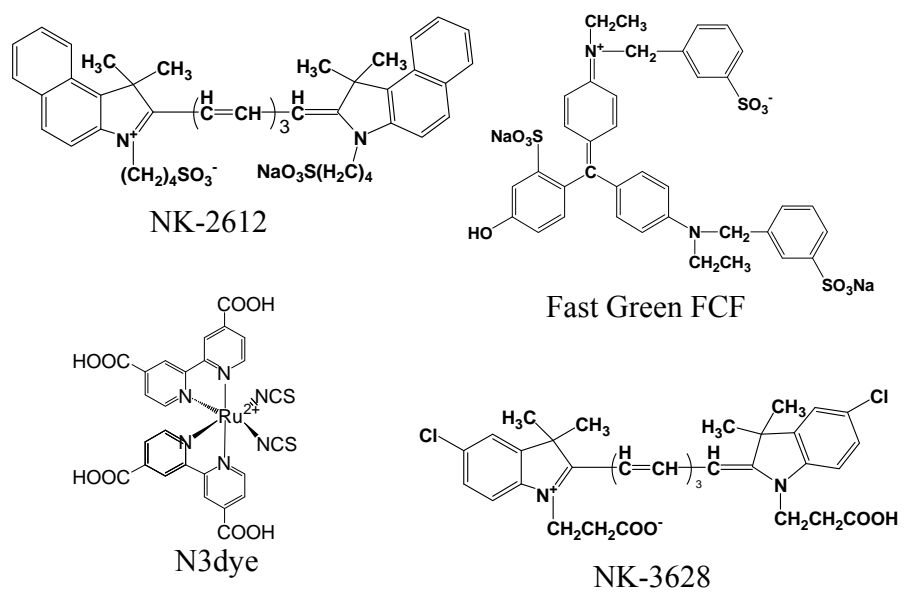

Figure 1. 


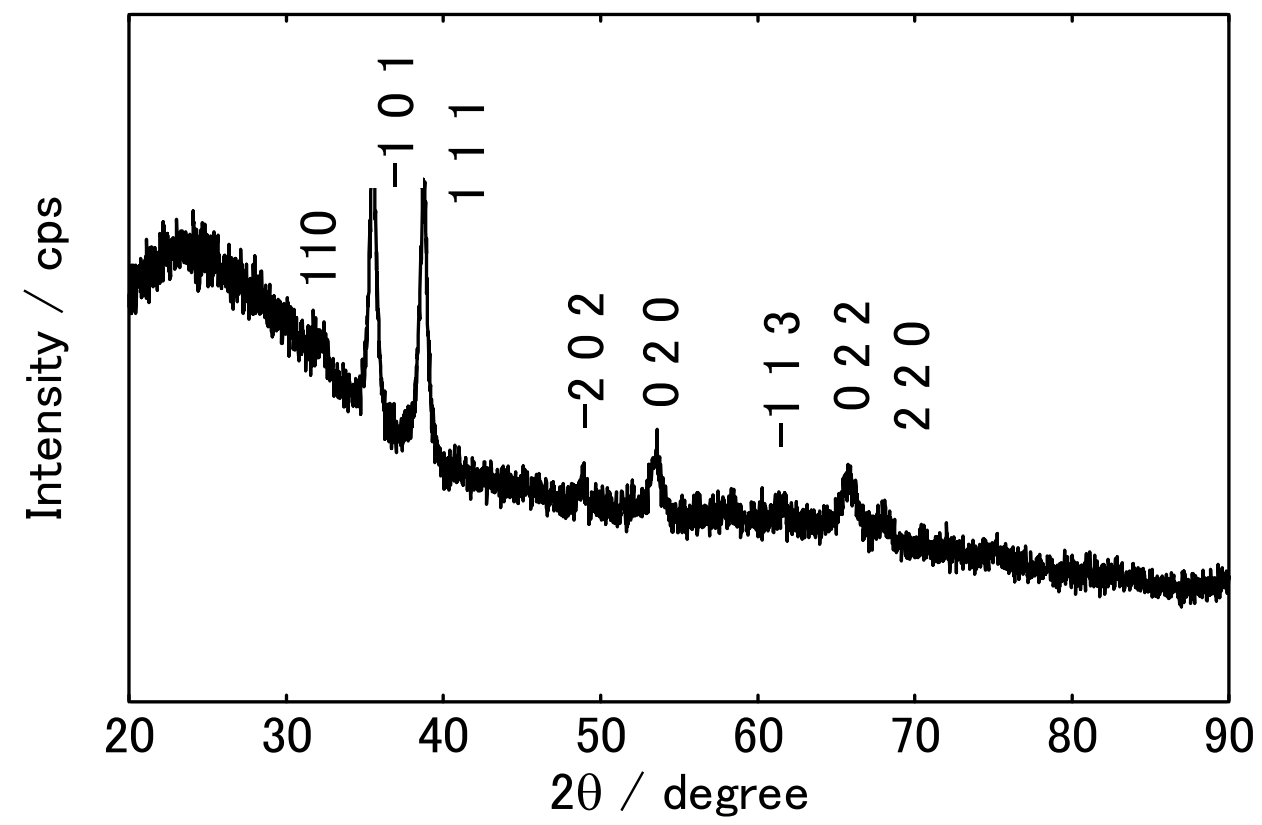

Figure. 2. 


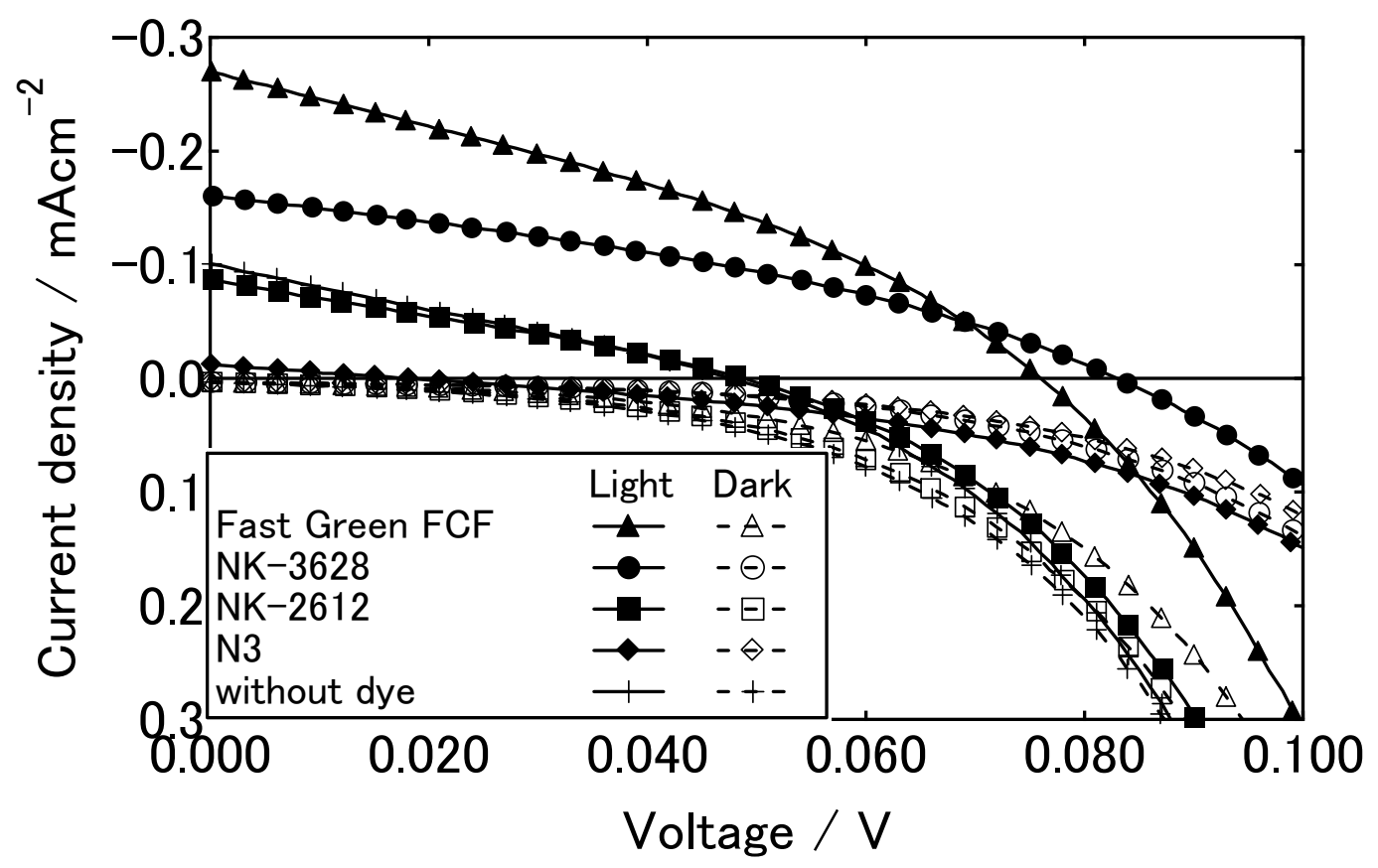

Figure 3. 


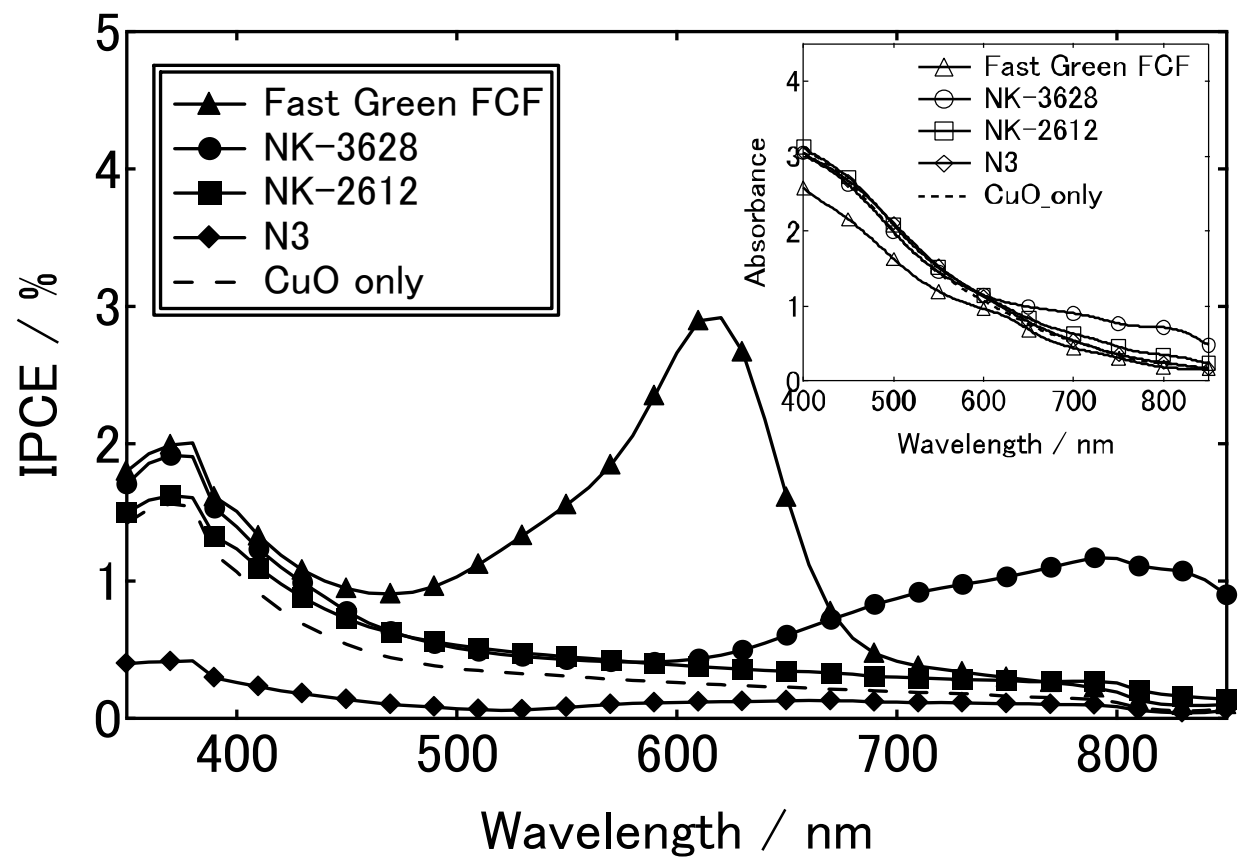

Figure 4. 


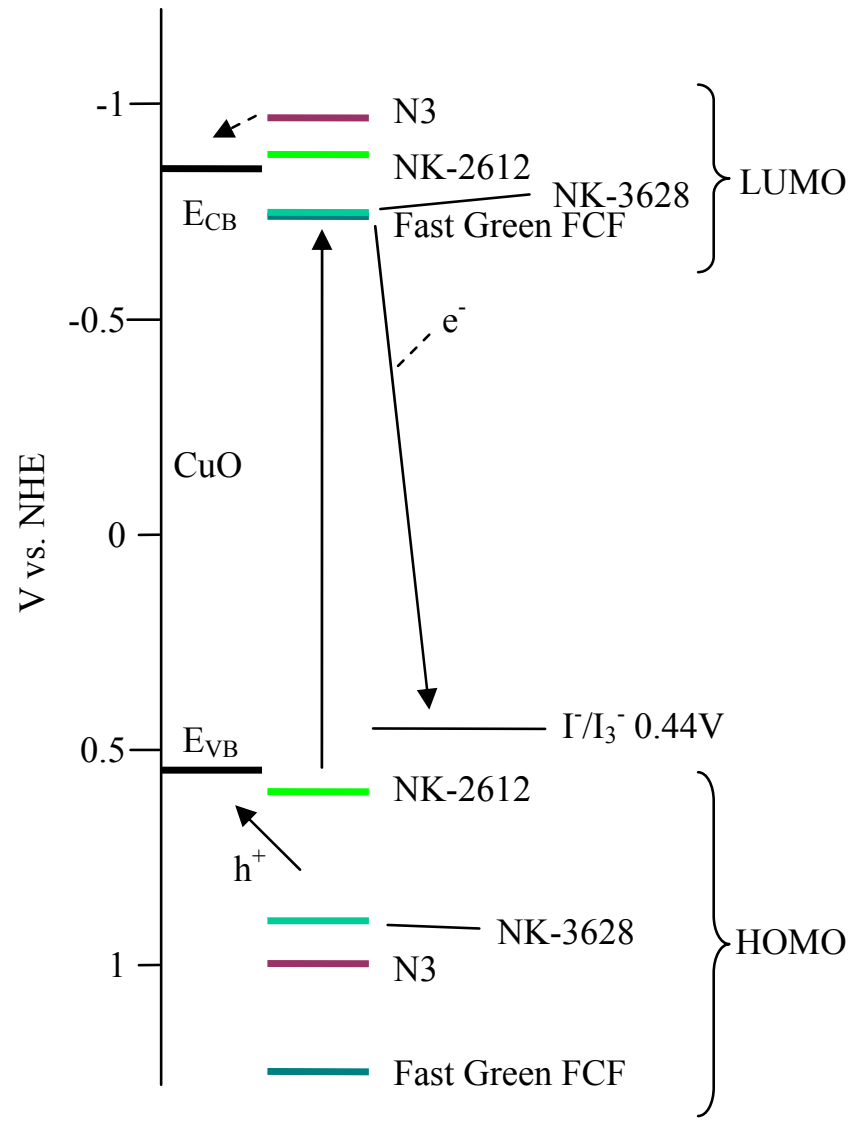

Figure 5. 


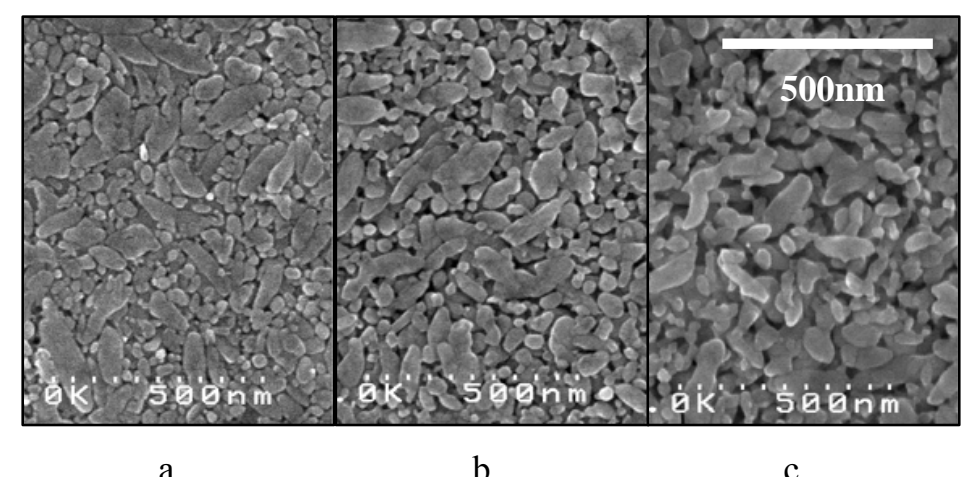

Figure 6. 


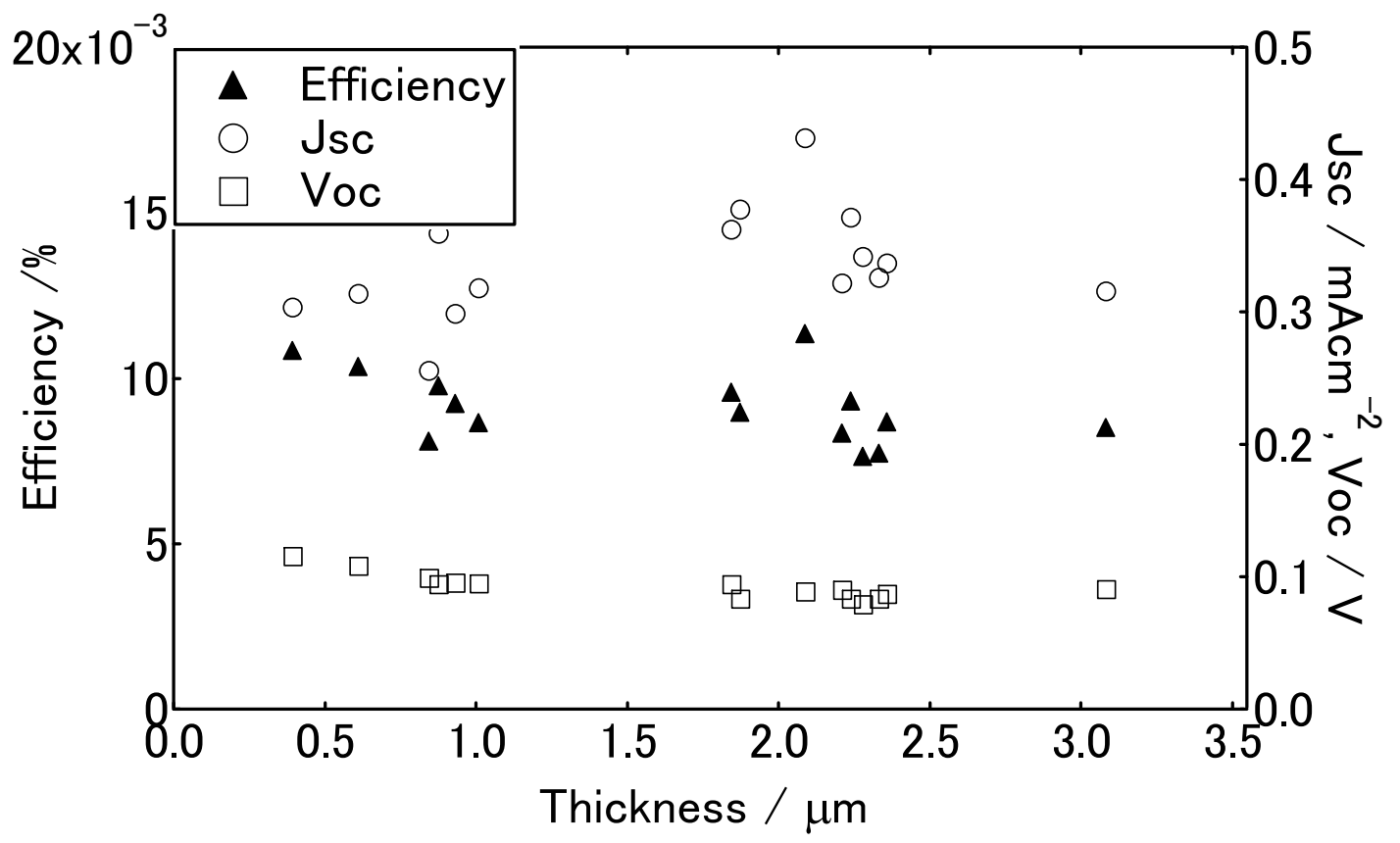

Figure 7. 